\title{
Correction to "Probing the Assembly of HDL Mimetic, Drug Carrying Nanoparticles Using Intrinsic Fluorescence"
}

\begin{abstract}
The above article [Raut S, Garud A, Nagarajan B, Sabnis N, Remaley A, Fudala R, Gryczynski I, Gryczynski Z, Dzyuba SV, Borejdo J, and Lacko A (2020) J Pharmacol Exp Ther 373:113-121; DOI: https://doi.org/10.1124/jpet.119.262899] was published with an incorrect copyright line. Although the paper is an open access article, the copyright line should state "U.S. government work not protected by U.S. copyright."
\end{abstract}

The HTML and PDF versions of the article have been corrected.

The compositor apologizes for this error. 